\title{
Typhlocolitis associated with Clostridium difficile ribotypes 078 and 110 in neonatal piglets from a commercial Irish pig herd
}

\author{
Máire C. McElroy ${ }^{1 *}$, Martin Hill ${ }^{1}$, Geraldine Moloney², Micheál Mac Aogáin², Shane McGettrick', \\ Áine $\mathrm{O}^{\prime}$ Doherty ${ }^{1}$ and Thomas R. Rogers ${ }^{2}$
}

\begin{abstract}
Background: Clostridium difficile is a recognised cause of typhlocolitis and diarrhoea in neonatal pigs but has never been confirmed in association with pathology and disease in Irish pigs.

Case Presentation: Four neonatal piglets, with a history of diarrhoea were referred to the Central Veterinary Research Laboratory, Backweston for necropsy. They were from a fully integrated, commercial pig farm with approximately 1000 sows. Three piglets had acute, superficial, erosive and suppurative typhlocolitis and the other had mild suppurative mesocolitis. Clostridium difficile (C. difficile) toxins A/B were detected using ELISA in the colonic contents from each piglet. C. difficile isolates from two of the piglets were PCR-ribotyped as 078 and an isolate from a third pig was ribotyped as 110 .
\end{abstract}

Conclusions: This is the first report confirming C. difficile in association with typhlocolitis in Irish pigs.

Keywords: Clostridium difficile, Typhlocolitis, Pigs, PCR ribotyping

Abbreviations: CDAD, Clostridium difficile-associated disease; PCR, Polymerase chain reaction

\section{Background}

Clostridium difficile is a toxin producing, Gram-positive, spore-forming, anaerobic enteropathogen of humans and animals. It has recently emerged as a major cause of porcine neonatal diarrhoea in America [1]. It has also been reported in association with neonatal diarrhoea in Europe although one study found no clear association between $C$. difficile isolation and diarrhoea [2, 3]. Porcine Clostridium difficile -associated disease (CDAD) typically manifests itself as early-onset diarrhoea and sudden death in piglets 1-7 days of age. Gross lesions may include mesocolonic oedema and large intestines may be filled with pasty to watery yellowish contents. Histopathological mucosal lesions are limited to the caecum and colon. They are typically mild, but vary from grossly inapparent, multifocal necrosis of surface epithelial cells to transmural necrosis. The classic lesions are segmental

\footnotetext{
* Correspondence: maire.mcelroy@agriculture.gov.ie

'Pathology Division, Central Veterinary Research Laboratory, Backweston

Campus, Celbridge, Co. Kildare, Ireland

Full list of author information is available at the end of the article
}

erosions of the epithelium with effusion of fibrin and neutrophils into the lumen, so-called "volcano ulcers" [4].

CDAD occurs when $C$. difficile proliferates after endogenous intestinal flora is disrupted, either by a change in diet or antimicrobial treatment [5]. C. difficile produces two major toxins, Toxin A (TcdA) and Toxin B (TcdB) that act synergistically to cause apoptosis of mucosal epithelial cells and disruption of intracellular actin filaments responsible for cell to cell adhesion. Consequently, there is increased permeability of mucosal surfaces. Toxins A and B also initiate an inflammatory cascade that can result in increased damage to host tissues and fluid exudation [6]. The requirements for development of CDAD are disruption of normal intestinal or colonic flora, presence of the organism in the environment, and the production of toxins [5].

The standard for diagnosis of porcine CDAD is detection of toxins $\mathrm{A}$ and $\mathrm{B}$ in faeces or colonic contents, generally using commercially available enzyme immunoassays. Cultivation of $C$. difficile is difficult to interpret 
because it can be found in healthy pigs, therefore its isolation may have little diagnostic relevance [4].

C. difficile is also one of the most important nosocomial pathogens of humans, primarily associated with intestinal dysbiosis due to antibiotic administration. In recent years the epidemiology of human disease is changing with more community-acquired infections and emergence of strains in humans that are common in domestic animals [5]. Therefore, considerable interest is developing in potential zoonotic capabilities of $C$. difficile.

The aims of this paper are to document typhlocolitis associated with $C$. difficile in an outbreak of diarrhoea in neonatal pigs from a commercial pig farm in Ireland and to report the strain typing results of the $C$. difficile isolates.

\section{Case presentation}

Four piglets, 3-4-days old, that had died during an outbreak of high morbidity, low mortality, neonatal diarrhoea in a 1000 sow commercial pig herd were submitted for necropsy. Details of treatment prior to death were not available.

At gross necropsy all four carcasses were well preserved with adequate body fat reserves. Stomachs were filled with milk. There was mild mesocolonic oedema, and small intestinal and colonic contents were soft and yellow in all four. No gross changes were noted in intestinal, caecal or colonic mucosa. Other body systems were unremarkable.

\section{Histopathology}

At least 6 sections from representative areas along the length of the small intestine, a section of caecum and at least six sections of spiral colon were sampled for histopathology. They were fixed in buffered formalin, processed routinely and stained with haematoxylin and eosin.

On histopathological examination three of the piglets had mild $(n=1)$ to severe $(n=2)$, multifocal, superficial fibrinosuppurative and erosive colitis with neutrophils and fibrin spilling from lamina propria through the eroded epithelium and into the lumen ('volcano lesions') (Fig. 1). In the other piglet there was a mild, multifocal, suppurative mesocolitis. In addition, in two of the piglets there was acute, mild, superficial, suppurative enteritis, with superficial necrosis and microthrombosis in one of the piglets. All four piglets also had mild atrophic enteritis.

\section{C. difficile toxin testing, isolation and PCR Ribotyping}

Colonic contents were positive for $C$. difficile toxins A/B using using Premier Elisa Kit Toxins A\&B (Meridian Bioscience Inc.)

Fifteen $\mu \mathrm{L}$ colonic contents were treated with $50 \mu \mathrm{L}$ (96\%) ethanol. Fifteen $\mu \mathrm{L}$ of each mixture was transferred individually to plates containing Brazier's cefoxitin cycloserine egg-yolk (CCEY) medium (Lister, 2014). Plates were incubated anaerobically $\left(10 \% \mathrm{H}_{2}, 10 \% \mathrm{CO}_{2}\right.$ and $\left.80 \% \mathrm{~N}_{2}\right)$ at $34{ }^{\circ} \mathrm{C}$ for $48 \mathrm{~h}$. 'Broken glass' colonies, typical of $\mathrm{C}$. difficile, were transferred to blood agar plates and incubated for a further $48 \mathrm{~h}$. Chelex-100 chelating resin was used for whole-cell DNA extraction of the resulting colonies. PCR-amplification of the DNA was performed with BioMix Red mastermix (Bioline) and CD-16s primers, 5' -CTG GGG TGA AGT CGT AAC AAG G-3', 6' -GCG CCC TTT GTA GCT TGA CC-3' (Eurofins MWG). PCR products were transferred to a heating block, set to $75^{\circ} \mathrm{C}$, for $45 \mathrm{~min}$ to concentrate products to c. $20 \mu \mathrm{L}$, before electrophoresis on a $3 \%$ agarose gel with GelGreen nucleic

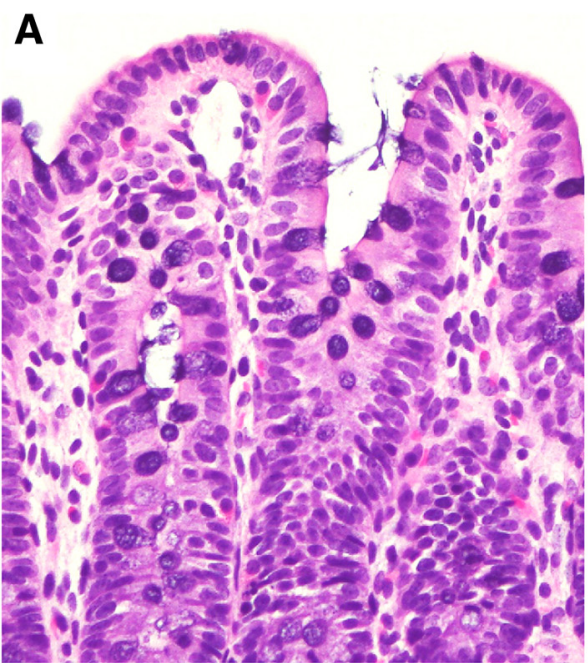

B

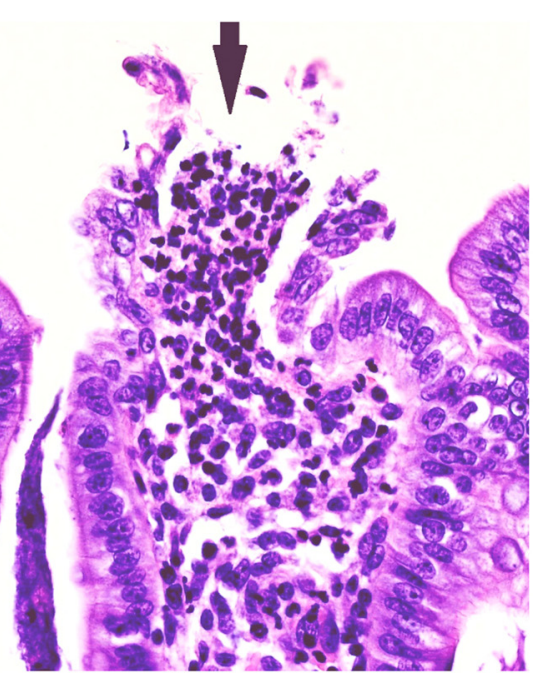

Fig. 1 Pig. Colon. a Normal colon lined by columnar epithelial cells. b Superficial, erosive colitis with infiltration of neutrophils into the lamina propria and effusion into the lumen - 'volcano lesion' (arrow) (Haematoxylin and eosin 20x) 
acid stain (Biotium). The gel was placed under ultraviolet light in a closed chamber of Bio-Rad Universal Hood II. Results were visualised with Bio-Rad Quantity One (4-6-1) 1-dimensional analysis software. PCR ribotypes were successfully obtained for three piglets; two were ribotype 078 and one was ribotype 110 . The fourth piglet's sample failed to yield a pure culture after treatment with $96 \%$ ethanol and anaerobic incubation with CCEY medium.

\section{Other laboratory testing}

Clostridium perfringens (C. perfringens) was isolated by direct anaerobic culture of intestinal contents using pre-reduced $5 \%$ Columbia sheep blood agar (SBA) and fastidious anaerobe blood agar with nheomycin (E\&O Laboratories, Scotland). C. perfringens alpha toxin was detected in a pooled sample of small intestinal contents using a sandwich ELISA, testing for alpha $(\alpha)$, beta $(\beta)$, epsilon $(\varepsilon)$ toxins and $C$. perfringens Antigen (BioX Diagnostics, Belgium).

Rotavirus group B was detected in small intestinal contents in two of the piglets using modified versions of previously described PCR methods [7, 8]. PCRs for porcine coronaviruses and porcine reproductive and respiratory virus were negative using modified versions of previously described methods [9-12]. No antigen was detected using anti-Cryptosporidium parvum monoclonal antibody labelled with fluorescein isothiocyanate (Bio-X Diagnostics, Belgium, Catalogue Number BIO 073).

\section{Conclusions}

This is the first confirmed report of typhlocolitis associated with $C$. difficile in Irish pigs. $C$. difficile infection in the four piglets here appeared to be acting only as one component in a multifactorial diarrhoea that also involved Group B rotaviruses and possibly Clostridium perfringens Type A. Ongoing surveillance is required to determine the relative significance of $C$. difficile in porcine neonatal diarrhoea in Ireland.

This is also the first report of PCR-ribotyping of C. difficile isolates from clinically affected Irish pigs. There are a number of different molecular methods available for strain typing, most commonly polymerase chain reaction (PCR)-based ribotyping, multilocus variable number tandem repeat analysis (MLVA), pulsed field gel electrophoresis (PFGE) and whole genome sequencing (WGS) $[13,14]$. PCR ribotype 078 is the most commonly reported isolate from pigs in most studies, including a recent Irish study in pigs of different ages [2, 14-16]. In one study in humans this strain was shown to have increased by at least 6-fold from 2000 to 2008 [17]. Moreover, genetically indistinguishable $C$. difficile 078 stains have been found in pigs and farmers, indicating interspecies transmission but the route of transmission has not been determined [18]. Therefore there is increasing interest in $C$. difficile as a 'One Health' issue. Our findings of two ribotypes in this one herd are consistent with previous reports of diversity of $C$. difficile ribotypes amongst pigs in an international study of animal associated strains, and a previous report from Germany $[19,20]$.

There are approximately 1600 new cases of human $C$. difficile infections per annum in Ireland, $21.5 \%$ of which are recognised to be community-acquired infections i.e. patients had not had admission to a healthcare facility for 12 weeks preceding symptom onset [21]. A UK study has shown that only $38 \%$ of CDAD in hospital inpatients can be attributed to transmissions within the hospital [22]. This has led to increased interest in the 'One Health' epidemiology of $C$. difficile. PCR ribotype results were available for only $16 \%$ of human cases in Ireland in 2014: ribotypes 078 and 014 were most frequently reported, both $11 \%$ of known results [21].

This report has confirmed that $C$. difficile is present in Irish pigs and is associated with typhlocolitis as part of multifactorial diarrhoea. Further studies are warranted to determine the prevalence of $C$. difficile in Irish pigs and other animal species. In addition, molecular typing studies using conventional methods such as PCR-based ribotyping or whole genome sequencing may provide information on any relationship that may exist between strains from animals and humans in Ireland.

\section{Acknowledgments}

The authors wish to thank Paul Spillane for referring the animals and providing the clinical history; the staff of the histopathology laboratory, CVRL, Backweston for processing the histopathology; the staff of Virology Division for carrying out the viral PCRs.

\section{Funding}

GM is recipient of Research Training Fellowship for Healthcare Professionals HPF-2014-716 (Health Research Board, Ireland).

Availability of data and materials

Paraffin-embedded tissue sections and Clostridium difficile isolates are available.

\section{Authors' contributions}

MMcE and SMcG carried out the necropsies. MMcE interpreted the histopathology and drafted the paper. GM did the PCR ribotyping and drafted part of the paper. $\mathrm{MH}$ and $\mathrm{AOD}$ carried out bacteriology and toxin ELISAs. All authors read and approved the final manuscript.

\section{Competing interests}

The authors declare that they have no competing interests.

\section{Consent for publication}

This paper relates to animals submitted for necropsy. All information relating to the farm of origin is anonymous. The need for written consent is not applicable.

\section{Ethics approval and consent to participate}

This case report relates to dead animals referred for necropsy so is exempt from ethics approval.

\section{Author details}

${ }^{1}$ Pathology Division, Central Veterinary Research Laboratory, Backweston Campus, Celbridge, Co. Kildare, Ireland. ²Department of Clinical Microbiology, Trinity College Dublin, Dublin, Ireland. 
Received: 11 June 2016 Accepted: 14 August 2016

Published online: 19 August 2016

\section{References}

1. Songer JG. The emergence of Clostridium difficile as a pathogen of food animals. Anim Health Res Rev. 2004;5:321-6.

2. Debast SB, van Leengoed LA, Goorhuis A, Harmanus C, Kuijper EJ, Bergwerff AA. Clostridium difficile PCR ribotype 078 toxinotype $V$ found in diarrhoeal pigs identical to isolates from affected humans. Environ Microbiol. 2009;2:505-11.

3. Álvarez-Pérez S, Blanco JL, Bouza E, Alba P, Gibert X, Maldonado J, García ME. Prevalence of Clostridium difficile in diarrhoeic and non-diarrhoeic piglets. Vet Microbiol. 2009:137:302-5.

4. Songer JG, Uzal FA. Clostridial enteric infections in pigs. J Vet Diagn Invest. 2005:17:528-36

5. Squire MM, Riley TV. Clostridium difficile infection in humans and piglets: a 'One Health' opportunity. Curr Top Microbiol Immunol. 2013;365:299-314.

6. Keel MK, Songer JG. The comparative pathology of Clostridium difficileassociated disease. Vet Pathol. 2006;43:225-40.

7. Marthaler D, Homwong N, Rossow K, Culhane M, Goyal S, Collina J, et al. Rapid detection and high occurrence of porcine rotavirus $A, B$, and C by RTqPCR in diagnostic samples. J Virol Methods. 2014;209:30-4.

8. Jothikumar N, Kang G, Hill VR. Broadly Reactive TaqMan ${ }^{\circledast}$ assay for real-time RT-PCR detection of rotavirus in clinical and environmental samples. J Virol Methods. 2009;155:126-31.

9. Seong-Hee K, In-Joong K, Hyun-Mi P, Dong-Seob T, Jae-Young S, Bang-Hun H. Multiplex real-time RT-PCR for the simultaneous detection and quantification of transmissible gastroenteritis virus and porcine epidemic diarrhea virus. J Virol Methods. 2007;146:172-7.

10. Mardassi H, Mounir S, Dea S. Identification of major differences in the nucleocapsid protein genes of a Quebec strain and European strains of porcine reproductive and respiratory syndrome virus. J Gen Virol. 1994;75: 681-5.

11. Egli C, Thur B, Liu L, Hofmann M. Quantative TagMan RT-PCR for the detection and differentiation of European and North American strains of porcine reproductive and respiratory syndrome virus. J Virol Methods. 2001; 98:63-75.

12. Frossard JP, Fearnley C, Naidu B, Errington J, Westcott DG, Drew TD. Porcine reproductive and respiratory syndrome virus: Antigenic and molecular diversity of British isolates and implication of diagnosis. Vet Microbiol. 2012; 158:308-15.

13. Brazier JS. Typing of Clostridium difficile. Clin Microbiol Infect. 2001;7:428-31.

14. Marsh JW, Harrison LH. Clostridium difficile: a food safety concern. In: Chen CY, Yan X and Jackson CR, editors. Antimicrobial Resistance and Food safety: Methods and Techniques. London: Elsevier; 2015. p. 181-206.

15. Keel K, Brazier JS, Post KW, Weese S, Songer JG. Prevalence of PCR ribotypes among Clostridium difficile isolates from pigs, calves, and other species. J Clin Microbiol. 2007;45:1963-4.

16. Stein K, Egan S, Lynch H, Harmanus C, Kyne L, Herra C, et al. Prevalence and PCR ribotype distribution of Clostridium difficile in pigs in Ireland. In: Proceedings $26^{\text {th }}$ European Congress of Clinical Microbiology and Infectious Diseases. 2016

17. Goorhuis A, Bakker D, Corver J, Debast SB, Harmanus C, Notermans DW, et al Emergence of Clostridium difficile infection due to a new hypervirulent strain, polymerase chain reaction ribotype 078. Clin Infect Dis. 2008;47:1162-70.

18. Knetsch CW, Connor TR, Mutreja A, van Dorp SM, Sanders IM, Browne HP, et al. Whole genome sequencing reveals potential spread of Clostridium difficile between humans and farm animals in the Netherlands, 2002 to 2011. Euro Surveill. 2014;19(45). Article DOI: http://dx.doi.org/10.2807/15607917.ES2014.19.45.20954. Accessed 17 Aug 2016.

19. Janezic S, Zidaric V, Pardon B, Indra A, Kokotovic B, Blanco JL, et al. International Clostridium difficile animal strain collection and large diversity of animal-associated strains. BMC Microbiol. 2014;14:173-83.

20. Schneeberg A, Neubauer H, Schmoock G, Baier S, Harlizius J, Nienhoff H, Brase K, Zimmermann S, Seyboldt C. Clostridium difficile genotypes in piglet populations in Germany. J Clin Microbiol. 2013:51:3796-803.
21. Clostridium difficile infection. In: Health Protection Surveillance Centre Annual Epidemiological Report 2014 http://www.hpsc.ie/AboutHPSC/AnnualReports/ File,15505,en.pdf. Accessed 17 Aug 2016.

22. Eyre DW, Cule ML, Wilson DJ, Griffiths D, Vaughan A, O'Connor L, et al. Diverse sources of $C$. difficile infection identified on whole-genome sequencing. N Engl J Med. 2013;369:1195-205.

\section{Submit your next manuscript to BioMed Central and we will help you at every step:}

- We accept pre-submission inquiries

- Our selector tool helps you to find the most relevant journal

- We provide round the clock customer support

- Convenient online submission

- Thorough peer review

- Inclusion in PubMed and all major indexing services

- Maximum visibility for your research

Submit your manuscript at www.biomedcentral.com/submit
Biomed Central 